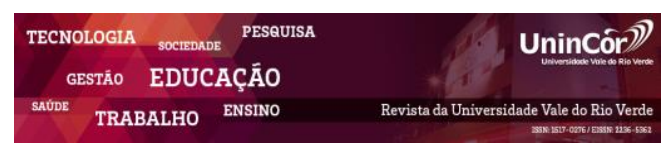

Revista da Universidade Vale do Rio Verde ISSN: 1517-0276 / EISSN: 2236-5362 v. $16\left|\mathbf{n}^{\circ} .3\right|$ Ano 2018

Ernani Carvalho Cornélio Junior Universidade Vale do Rio Verde (UninCor) ernani-junior1990@ hotmail.com

Aurivan Soares de Freitas Universidade Vale do Rio Verde (UninCor) aurivan.soares@hotmail.com

Eliana Alcantra

Universidade Vale do Rio Verde (UninCor) lialcantra@yahoo.com.br; prof.eliana.alcantra@unincor.edu.br

Ramiro Machado Rezende Universidade Vale do Rio Verde (UninCor) coord.agronomia@unincor.edu.br

Mirian de Lourdes Oliveira e Silva olivemiri@gmail.com

Daynan Ferreira Ribeiro Agrônomo daynan_fr@hotmail.com

\section{INCIDÊNCIA DE FERRUGEM, CERCOSPORIOSE E MANCHA DE Phoma EM CAFEEIRO SOB DIFERENTES TIPOS DE PODA}

\section{RESUMO}

O cafeeiro (Coffea arabica L.) está entre as principais culturas do agronegócio brasileiro. Entretanto, essa espécie é afetada por diversas doenças, incluindo: ferrugem, cercosporiose e mancha de Phoma. Entre as práticas culturais realizadas em cafezais velhos, destacam-se as podas, as quais podem enfraquecer as plantas e aumentar a intensidade de doenças. Diante do exposto, objetivouse com o presente trabalho, avaliar o efeito dos diferentes tipos de podas na incidência das principais doenças do cafeeiro. Avaliouse, no período de maio de 2017 a maio de 2018 , a incidência da ferrugem, cercosporiose e mancha de Phoma e o enfolhamento em plantadas submetidas a diferentes tipos de poda. Houve variação na intensidade das doenças ao longo do período avaliado, com os maiores picos entre maio e julho de 2017. Os dados das avaliações das doenças foram integrados a área abaixo da curva de progresso da incidência (AACPI). A maior AACPI da ferrugem ocorreu nos talhões com plantas de Mundo Novo Acaiá recepadas e Mundo Novo Acaiá esqueletado. A cercosporiose apresentou maior AACPI nos talhões com Mundo Novo Acaiá recepados e Catuaí vermelho não podado. Já a Mancha de Phoma, apresentou maior AACPI no talhão com Catucaí não podado. Em relação ao enfolhamento, houve menor porcentagem nos talhões com Catuaí vermelho não podado e Mundo Novo Acaiá, recepado.

Palavras-chave: Coffea arabica L., Hemileia vastatrix, Cercospora coffeicola, Phoma tarda, Enfolhamento.

\section{INCIDENCE OF RUST, CERCOSPORIOSIS AND Phoma SPOT IN COFFEE UNDER DIFFERENT TYPES OF PRUNING}


AACPI nos talhões com mundo novo acaiá recepado e catuaí vermelho não podado. Já a Mancha de Phoma, apresentou maior AACPI no talhão com catucaí não podado. Em relação ao enfolhamento, houve menor porcentagem nos talhões com catuaí vermelho não podado e mundo novo acaiá, recepado.

Keywords: Coffea arabica L., Hemileia vastatrix, Cercospora coffeicola, Phoma tarda, Leafing.

Recebido em: 03/09/2018 - Aprovado em: 03/12/2018 - Disponibilizado em: 30/12/2018

\section{INTRODUÇÃO}

O cafeeiro (Coffea arabica L.) está entre as principais culturas para agronegócio brasileiro, estando entre os mais importantes produtos da pauta de exportações. Em 2017, o Brasil foi o maior produtor e exportador de café do mundo, com 44, 97 milhões de sacas (CONAB, 2017). Assim, a cultura do cafeeiro tem grande importância sócioeconômica para o país. Apesar desses dados expressivos, diversos fatores têm limitado ou reduzido essa produção, dentre os quais se destacam a ocorrência de doenças, como a ferrugem (Hemileia vastatrix), a cercosporiose (Cercospora coffeicola) e a mancha de Phoma (Phoma tarda).

A ferrugem ocorre em todas as regiões produtoras de café do mundo causando perdas em torno de $35 \%$ na produção, quando as condições climáticas são favoráveis. Todavia, em condições de estiagem prolongada no período de maior severidade da doença, as perdas na produção podem chegar a mais de 50\% (ZAMBOLIM, 2016).
Os urediniósporos são fontes de inóculo que requerem água no estado líquido para germinar e penetrar na planta pelos estômatos. A disseminação ocorre rapidamente na lavoura por meio da ação do vento, pelas gotas de chuva, pelo escorrimento de água das margens do limbo para a superfície inferior, pelo homem durante a execução dos tratos culturais e transportes, e por insetos e outros animais que entram em contato com plantas infectadas (MORAES, 1983).

De forma semelhante, a cercosporiose causa danos em cafeeiros, principalmente, em lavouras sem fertilização adequada. Após atingir novas folhas e frutos do cafeeiro, os conídios na presença de umidade favorável germinam e o tubo germinativo penetra diretamente pela cutícula ou por aberturas naturais, colonizando o tecido hospedeiro (ZAMBOLIM, 2016). Essa doença é importante em lavouras estabelecidas em condições ambientais de insolação excessiva. Além disso, o estresse hídrico e a adubação insuficiente ou desequilibrada podem proporcionar maior índice da doença (SOUZA et al., 2015). 
A mancha de Phoma tem sido problemática em áreas cafeeiras com altitudes superiores a $900 \mathrm{~m}$ sujeitas a ventos frios, principalmente, nos anos com excesso de chuvas de inverno. Segundo Zambolim (2009), fatores climáticos e nutricionais podem predispor a planta ao ataque desse patógeno. A espécie $P$. tarda tem ocorrência limitada pela temperatura e umidade. A mancha de Phoma é favorecida por ventos fortes e frios, granizo, geadas, temperatura média entre 19 e $20^{\circ} \mathrm{C}$. Além disso, desequilíbrios nutricionais podem predispor as plantas ao ataque do patógeno devido ao esgotamento dos ramos produtivos.

Nos últimos anos, diante da necessidade de renovar os cafezais, tem crescido a prática da poda, visando manter a estrutura de ramos produtivos, facilitar colheita e os tratos culturais.

A poda do cafeeiro é uma prática bastante difundida entre os cafeicultores, principalmente em lavouras que sofreram alguns efeitos abióticos, e em cafezais mais velhos que apresentam sua produção reduzida não apresentando valor econômico. O corte das plantas é realizado em lavouras que receberam ataque intenso de pragas ou doenças (MATIELLO et al., 2010).

As podas usuais em lavouras de café podem ser agrupadas em 2 tipos principais: As podas drásticas e as podas leves. As podas drásticas incluem a recepa e o esqueletamento, levando a eliminação da maior parte da ramagem ou da haste principal do cafeeiro, com isso sendo perdida toda a copa justificando o nome pelo efeito drástico na estrutura vegetativa da planta e a sua produtividade em curto prazo. As podas leves abrangem o decote, as podas de limpeza e no cafeeiro Conillon, a poda de produção. Nesse tipo de poda, eliminam-se pequenas partes do cafeeiro, que assim perde pouco da sua produção e em certos casos chega a ganhar produtividade no curto prazo de tempo (MESQUITA et al., 2016a; MESQUITA et al., 2016b).

Após a poda, o cafeeiro se comporta como uma planta nova, o que demanda cuidados especiais, pois os problemas fitossanitários, como a ocorrência de doenças podem aumentar. Assim, entender o comportamento do progresso das doenças do cafeeiro nos diferentes tipos de poda torna-se imprescindível para a implantação das medidas de manejo. Diante do exposto, objetivou-se com o presente trabalho, avaliar o efeito de diferentes tipos de podas na incidência da ferrugem, cercosporiose e mancha de Phoma do cafeeiro.

\section{MATERIAL E MÉTODOS}

O experimento foi conduzido entre maio de 2017 e maio de 2018, na Fazenda Coimbra, localizada na Comunidade Serra das Abelhas, no município de Três Corações, MG, cujas coordenadas geográficas são $21^{\circ}$ 
34' 04" de latitude Sul e $45^{\circ} 12$ ' $00^{\prime \prime}$ de longitude Oeste e altitude média de $912 \mathrm{~m}$, apresentando clima tipo tropical. O solo da área é do tipo Latossolo Vermelho
Distroférrico. $\mathrm{Na}$ área, encontrava-se plantado quatro talhões de cafeeiro com diferentes idades e sistemas de poda (Tabela $1)$.

Tabela 1. Características dos talhões utilizados para avaliar o enfolhamento e a incidência de doenças no cafeeiro

\begin{tabular}{cccccc}
\hline Talhão & Tipo de poda & Cultivar & Idade (anos) & Espaçamento (m x m) & Número de plantas \\
\hline 1 & Não podado & Catuaí Vermelho & 5 & $3,80 \times 0,75$ & 11.930 \\
2 & Recepado & Mundo Novo Acaiá & 29 & $3,80 \times 0,75$ & 8.300 \\
3 & Esqueletado & Mundo Novo Acaiá & 29 & $3,80 \times 0,75$ & 8.300 \\
4 & Não podado & Catucaí Amarelo & 9 & $3,50 \times 0,80$ & 10.357 \\
\hline
\end{tabular}

Em cada talhão foram marcadas 20 plantas aleatoriamente nas quais avaliou-se, uma vez por mês, a incidência de ferrugem, cercosporiosee mancha de Phoma e o enfolhamento.

As avaliações foram realizadas por método não destrutivo em 10 ramos por planta escolhidos ao acaso. A ferrugem e a cercosporiose foram avaliadas no terço médio da copa, no terceiro e no quarto par de folhas. Já para a mancha de Phoma, as avaliações foram realizadas no terço superior das plantas e no primeiro e segundo par de folhas. A incidência de cada doença foi determinada pela porcentagem de folhas com sintomas em relação ao total amostrado, de acordo com a seguinte equação:

$$
\mathrm{I}(\%)=\frac{\mathrm{NFD}}{\mathrm{NFT}} * 100
$$

Em que:

$\mathrm{I}(\%)$ = incidência $(\%)$

$\mathrm{NFD}=$ número de folhas doentes

$\mathrm{NFT}=$ número de folhas por parcela

Nas mesmas datas de avaliação das doenças, foi avaliado o enfolhamento, por meio da escala diagramática proposta por Boldini (2001), sendo nota 1 (0 a $20 \%$ de enfolhamento), 2 (21 a 40\%), 3 (41 a 60\%), 4 (61 a $80 \%)$ e 5 (81 a 100\%).

Com os dados médios de incidência e de enfolhamento, de todos os talhões amostrais foi plotada a curva de progresso ao longo do tempo. Os dados das avaliações das doenças foram integralizados em área abaixo da curva de progresso da incidência (AACPI) de acordo com equação proposta por Shaner \& Finney (1977): 


$$
\mathrm{AACPI}=\sum_{i=1}^{n-1}\left(\frac{\left(y_{i}+y_{i+1}\right.}{2}\right)\left(t_{i+1}-t_{i}\right)
$$

Em que:

yi= proporção da doença na i-ésima observação;

ti= tempo, em dias, na i-ésima observação;

$\mathrm{n}=$ número total de observações.

Os dados da AACPI e do enfolhamento foram submetidos à análise de variância (ANOVA). As variáveis significativas no teste $\mathrm{F}$ foram comparadas, por meio do teste de Scott-Knott, a 5\% de probabilidade no software SISVAR (FERREIRA, 2011).

\section{RESULTADO E DISCUSSÃO}

As doenças do cafeeiro, ferrugem, cercosporiose e mancha de Phoma, ocorreram com intensidades variáveis durante a condução do experimento. No primeiro ano, os maiores picos de ferrugem e cercosporiose ocorreram entre maio e julho de 2017. Já para a mancha houve um pico elevado em agosto de 2017. A partir de fevereiro de 2018, a incidência das três doenças voltou a subir novamente (Figura 1). Silva et al. (2019) estudando a ferrugem do cafeeiro cultivado em sistema de irrigação por pivô central constataram maior incidência dessa doença em agosto de 2013 em junho e agosto de 2014. No mesmo sistema, Custódio et al. (2014) também observaram maior incidência da doença nos meses de agosto de 2004 e entre julho e agosto de 2005. Em lavouras não irrigadas no Triângulo Mineiro (CARVALHO \& CHALFOUN, 1998) e na Zona da Mata, ambas no estado de Minas Gerais, região sudeste do Brasil, Silva-Acuña et al. (1998) observaram as maiores incidências entre maio e setembro. Ou seja, pode ocorrer variação com relação aos períodos de máxima incidência da doença, tanto de um ano para outro, quanto de uma região para outra, confirmando a influência das variações climáticas, da produtividade, da fertilidade do solo, da nutrição da planta e das técnicas de cultivo e manejo fitossanitário (POZZA \& ALVES, 2008).

Em relação ao enfolhamento, houve menor índice nos meses de maior incidência da doença (Figura 1). Resultados semelhantes foram encontrados por Cunha et al. (2004) ao verificarem que a desfolha foi significativamente maior (49\%) em 2001, ano de maior incidência da ferrugem.

Para a ferrugem do cafeeiro, a maior área abaixo da curva de progresso da incidência (AACPI) foi constatada nos talhões $2(65,61)$ e $3(65,61)$, seguida pelos talhões 1 e 4, com valores de 36,56 e 0,825, respectivamente (Figura 2). A menor incidência da doença no talhão 4 pode ser atribuída ao fato dessa cultivar apresentar nível favorável de resistência (MENDONÇA et al., 2007). Em relação à luz Cústodio et al. 
(2010) verificaram que a intensidade da ferrugem foi maior na face de menor exposição à luz solar, o que pode em parte confirmar esses resultados.

Figura 1 - Curva de progresso da incidência da ferrugem, cercosporiose e mancha de Phoma do cafeeiro (a) e do enfolhamento (b) entre o período de 01/05/2017 a 01/06/2018
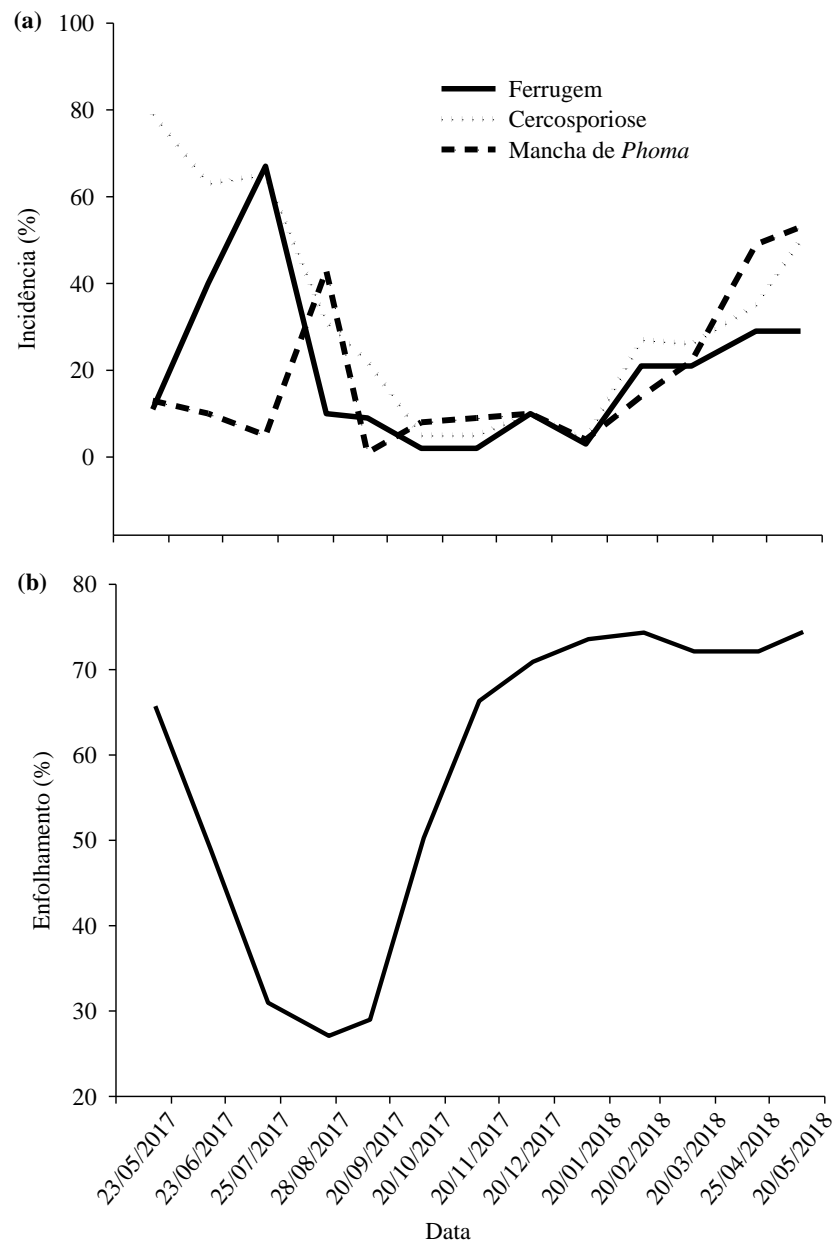

Em relação à cercosporiose a maior AACPI foi no talhão 2 (92,07), seguido pelo talhão 1 com 66,67, e os menores índices foram verificados nos talhões 3 e 4, com 44,63 e 30,76, respectivamente (Figura 2). Segundo Pozza et al. (2010) ocorre influência significativa da face de exposição da planta, com maior incidência na doença na face norte das plantas. Assim, a maior exposição à radiação solar direta pode ter favorecido o progresso da cercosporiose em folhas do cafeeiro.

A mancha de Phoma foi mais intensa no talhão 4, com AACPI de 58,77. Os demais tratamentos apresentaram AACPI de $12,65,15,37$ e 8,67 nos talhões 1,2 e 3, respectivamente (Figura 2). A maior intensidade da doença no talhão 4, certamente foi devido ao microclima favorável para a ocorrência da doença, já que 
nesse talhão não foi realizado a poda. Segundo Santos et al. (2014) um dos fatores que favorecem mancha de Phoma é a umidade relativa elevada. Almeida \& Matiello (1989) quantificaram perdas de $15 \%$ a $43 \%$ na produção de cafeeiro devido à infecção de Phoma tarda na parte superior da planta, mas isso ocorreu em regiões favoráveis à doença com temperatura em torno de $20{ }^{\circ} \mathrm{C}$ e umidade relativa superiora $80 \%$.

Figura 2 - Área abaixo da curva de progresso da incidência da ferrugem, cercosporiose e macha de Phoma (AACPI) em função de diferentes tipos de podas em cafeeiro.

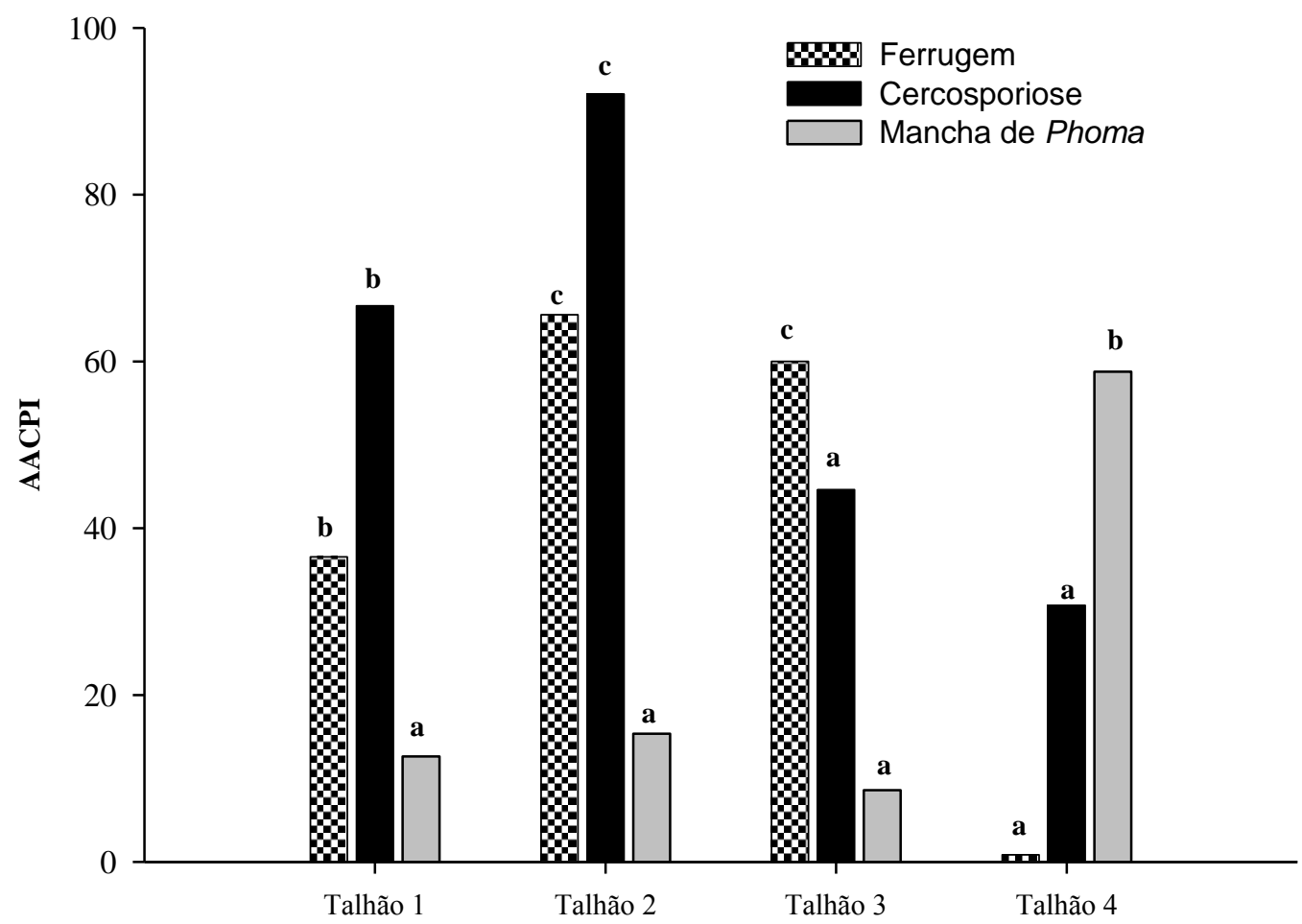

Talhão 1, Catuaí vermelho não podado; Talhão 2, Mundo Novo e Acaiá, recepados; Talhão 3, Mundo Novo e Acaiá, esqueletados; Talhão 4, Catucaí não podado. Médias das barras com cores e letras iguais não diferem estatisticamente por meio do teste de Scott-Knott, a 5\% de probabilidade.

Em relação ao enfolhamento, observou-se menor porcentagem $(41,82 \%)$ no talhão 1 , seguido pelo talhão 2 , com $50,43 \%$ de enfolhamento. Todavia, nos talhões 3 e 4 , houve índice de enfolhamento de $66,49 \%$ e $67,25 \%$, respectivamente (Figura 3). Segundo Pereira et al. (1997) a importância da área foliar de uma cultura é amplamente conhecida por ser um parâmetro indicativo de produtividade, pois o processo fotossintético depende da interceptação da energia luminosa e a sua conversão em energia química. Assim sendo, a superfície foliar de uma planta é a base do rendimento 
potencial da cultura. Além disso, o conhecimento da área foliar da planta permite a estimativa da perda de água, uma vez que as folhas participam no processo transpiratório, responsável pela troca gasosa com o ambiente. A menor porcentagem de enfolhamento nos talhões 1 e 2 , pode ser atribuída a fato da ferrugem e cercosporiose causarem queda de folha, pois nessas áreas houve maior incidência dessas doenças (SANTOS et al., 2008).

Figura 3 - Porcentagem de enfolhamento em função de diferentes tipos de podas em cafeeiro

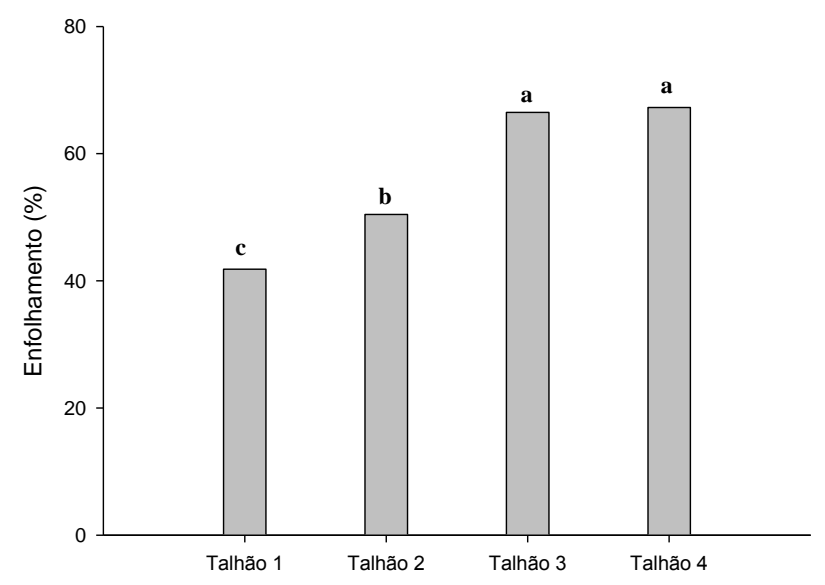

Talhão 1, catuaí vermelho não podado; Talhão 2, mundo novo acaiá, recepado; Talhão 3, mundo novo acaiá, esqueletado; Talhão 4, catucaí não podado. Médias das barras seguidas pela mesma letra não diferem estatisticamente por meio do teste de Scott-Knott, a $5 \%$ de probabilidade.

\section{CONCLUSÃO}

-As principais doenças do cafeeiro (ferrugem, cercosporiose e mancha de Phoma) apresentam curva de progresso com intensidades variáveis ao longo do ano.

-Os diferentes tipos de podas no cafeeiro influenciam na intensidade da ferrugem, cercosporiose e mancha de Phoma.
-A maior AACPI da ferrugem, cercosporiose e mancha de Phoma ocorre nos talhões com Mundo Novo Acaiá recepado e Novo Acaiá esqueletado, Mundo Novo Acaiá recepado e Catuaí Vermelho não podado e Catucaí não podado, respectivamente. 


\section{REFERÊNCIAS}

ALMEIDA, S.R.; MATIELLO, J.B. Estudo de novos produtos para controle químico a Phoma spp. em cafeeiros, a nível de campo. In: Congresso Brasileiro de Pesquisas Cafeeiras, 15. 1989, Maringá, Anais. 1989. p.145-146.

BOLDINI, J. M. Epidemiologia da ferrugem e da cercosporiose em cafeeiro irrigado e fertirrigado. 2001. 67p. Dissertação (Mestrado em Fitopatologia) - Universidade Federal de Lavras, Lavras.

CARVALHO, V. L.; CHALFOUN, S. M. Manejo integrado das principais doenças do cafeeiro. In: EPAMIG (ed.). Cafeicultura: Tecnologia para Produção. Belo Horizonte: Informe Agropecuário, 1998. p.27-35.

COMPANHIA NACIONAL DE ABASTECIMENTO - CONAB. Levantamentos de Safra: $\mathbf{2}^{\circ}$ levantamento da safra café: safra 2016/2017. Brasília: CONAB, 2017.

CUNHA, R. L., MENDES, A. N. G., \& CHALFOUN, S. M. Controle químico da ferrugem do cafeeiro (Coffea arabica L.) e seus efeitos na produção e preservação do enfolhamento. Ciência e Agrotecnologia, v. 28, n. 5, p. 990-996, 2004.

CUSTÓDIO, A. A. P., POZZA, E. A., DE PAIVA CUSTÓDIO, A. A., DE SOUZA, P. E., LIMA, L. A., \& DE LIMA, L. M. Intensidade da ferrugem e da cercosporiose em cafeeiro quanto à face de exposição das plantas. Coffee Science, Lavras, v. 5, n. 3, p. 214-228, set./dez. 2010.

CUSTÓDIO, A.A.P.; POZZA, E.A.; CUSTÓDIO, A.A.P, SOUZA, P.E.; LIMA, L.A.; SILVA, A. M. Effect of Center-Pivot Irrigation in the Rust and Brown Eye Spot of Coffee, Plant Disease, v. 98, n. 7, p. 943-947, 2014.

FERREIRA, D. F. Sisvar: a computer statistical analysis system. Ciência e agrotecnologia, v. 35, n. 6, p. 1039-1042, 2011.

MATIELLO, J. B.; ROSA, Gustavo NGP; LEITE FILHO, Sinésio. Diversos tipos de podas na recuperação de cafeeiros na Zona da Mata de Minas. 2010.
MENDONÇA, L. M. V. L., PEREIRA, R. G. F. A., MENDES, A. N. G., BORÉM, F. M., \& MARQUES, E. R. Composição química de grãos crus de cultivares de Coffea arabica L. suscetíveis e resistentes à Hemileia vastatrix Berg et Br. Ciência e Agrotecnologia, Lavras, v. 31, n. 2, p. 413-419, 2007.

MESQUITA, Carlos Magno de et al. Manual do café: distúrbios fisiológicos, pragas e doenças do cafeeiro (Coffea arabica L.). Belo Horizonte: EMATER-MG, 2016a. 62 p. il. CDU $633.73(21)$

MESQUITA, Carlos Magno de et al. Manual do café: manejo de cafezais em produção. Belo Horizonte: EMATER-MG, 2016b. 72 p. il CDU: 633.73(021).

MORAES, S. A. A ferrugem do cafeeiro: importância, condições predisponentes, evolução e situação no Brasil. Instituto Agronômico de Campinas, Campinas, 1983. 50p.

POZZA, E. A.; CARVALHO, V. L.;

CHALFOUN, S. M. Sintomas de injúrias causadas por doenças em cafeeiro. Semiologia do cafeeiro: sintomas de desordens nutricionais, fitossanitárias e fisiológicas. Lavras: UFLA, p. 69-101, 2010.

POZZA, E. A.; ALVES, M. C. Impacto potencial de mudanças climáticas sobre as doenças fúngicas do cafeeiro no Brasil. In: Raquel Ghini; Emilia Ramada. (Org.). Mudanças climáticas: impactos sobre doenças de plantas no Brasil. 1. ed. Brasília: Embrapa Informação Tecnológica, 2008. 331 p.. 1ed.Brasília: Gráfica: EMBRAPA, 2008, v. 1, p. 220-238.

SHANER, G.; FINNEY, R. E. The effect of nitrogen fertilization on the expression of slowmildew inresistance in Know wheat. Phythopatology, v. 67, p. 1051-1056, 1977.

SANTOS, L. S. D., POZZA, E. A., DE FARIA, M. A., DE LOURDES OLIVEIRA, M., DE PAIVA CUSTÓDIO, A. A., VASCO, G. B., \& DE MELO, B. M. Incidência da mancha de Phoma em cafeeiro irrigado por gotejamento, sob diferentes manejos de água. Coffee Science, v. 9, n. 1, p. 77-89, 2014. 
SANTOS, F. D. S., SOUZA, P. E. D., POZZA, E. A., MIRANDA, J. C., CARVALHO, E. A., FERNANDES, L. H. M., \& POZZA, A. A. A. Adubação orgânica, nutrição e progresso de cercosporiose e ferrugem-do-cafeeiro. Pesquisa. agropecuária brasileira, Brasília, v.43, n.7, p.783-791, jul. 2008.

SILVA, M. G., POZZA, E. A., VASCO, G. B., FREITAS, A. S., CHAVES, E., PAULA, P. V. A. A., $\ldots$ \& POZZA, A. A. A. (2019). Geostatistical analysis of coffee leaf rust in irrigated crops and its relation to plant nutrition and soil fertility. Phytoparasitica, p. 1-18.

SILVA-ACUÑA, R.; ZAMBOLIM, L.; CRUZ, C. D.; VALE, F. X. R. Estudo epidemiológico da ferrugem do cafeeiro (Hemileia vastatrix) utilizando a análise de trilha. Fitopatologia Brasileira, Brasília, v. 23, n. 4, p. 425-430, dez. 1998

SOUZA, A. G. C., MAFFIA, L. A., SILVA, F. F., MIZUBUTI, E. S. G., \& TEIXEIRA, H. A time series analysis of brown eye spot progress in conventional and organic coffee production systems. PlantPathology, v. 64, n.1, p.157-166, 2015.

ZAMBOLIM, L. Doenças do cafeeiro. In: AMORIM, L.; REZENDE, J. A. M.; BERGAMIN FILHO, A.; CAMARGO, L. E. (Ed.). Manual de Fitopatologia. vol. 2: Doenças das plantas cultivadas. 5. ed. Ouro Fino - MG:

Ceres. 2016. p.193-213.

ZAMBOLIM, L. Tecnologias para produção do café conilon. MARTINS, AG; PREZOTI, LC; Fertilização do cafeeiro, 2009.

\section{Ramiro Machado Rezende}

Mestre e doutor em Fitotecnia pela Universidade Federal de Lavras (UFLA). Professor Doutor.

Universidade Vale do Rio Verde (UninCor).

\section{Mirian de Lourdes Oliveira e Silva}

Mestre em Engenharia Mecânica pela Universidade de São Paulo (USP). Doutora em Engenharia Agrícola (Irrigação e Drenagem) pela Universidade Federal de Lavras (UFLA).

\section{Daynan Ferreira Ribeiro}

Bacharel em Agronomia pela Universidade Vale do Rio Verde (UninCor), Três Corações, Minas Gerais.

\section{Ernani Carvalho Cornélio Junior \\ Bacharel em Agronomia pela Universidade Vale do Rio Verde (UninCor), Três Corações, Minas Gerais.}

\begin{tabular}{l}
\hline Aurivan Soares de Freitas \\
Mestre e doutor em Fitopatologia pela Universidade \\
Federal de Lavras (UFLA). Professor na \\
Universidade Vale do Rio Verde (UninCor). \\
\hline
\end{tabular}

\section{Eliana Alcantra}

Mestre e doutora em Entomologia pela Universidade Federal de Lavras (UFLA). Professora na Universidade Vale do Rio Verde (UninCor). 